Article

\title{
Innovative Magnetite Based Polymeric Nanocomposite for Simultaneous Removal of Methyl Orange and Hexavalent Chromium from Water
}

\author{
Norah Salem Alsaiari ${ }^{1}$, Abdelfattah Amari ${ }^{2,3, *}$, Khadijah Mohammedsaleh Katubi ${ }^{1, *}$, \\ Fatimah Mohammed Alzahrani ${ }^{1, *(\mathbb{D})}$, Faouzi Ben Rebah ${ }^{4,5, *(\mathbb{D})}$ and Mohamed A. Tahoon 4,6 (D)
}

1 Chemistry Department, College of Science, Princess Nourah Bint Abdulrahman University, Riyadh 11671, Saudi Arabia; nsalsaiari@pnu.edu.sa

2 Department of Chemical Engineering, College of Engineering, King Khalid University, P.O. Box 9004, Abha 61413, Saudi Arabia

3 Research Laboratory: Energy and Environment, Chemical Engineering Department, National School of Engineers, Gabes University, Gabes 6072, Tunisia

4 Department of Chemistry, College of Science, King Khalid University, P.O. Box 9004, Abha 61413, Saudi Arabia; tahooon_87@yahoo.com

5 Higher Institute of Biotechnology of Sfax (ISBS), Sfax University, P.O. Box 263, Sfax 3000, Tunisia

6 Chemistry Department, Faculty of Science, Mansoura University, Mansoura 35516, Egypt

* Correspondence: abdelfattah.amari@enig.rnu.tn (A.A.); kmkatubi@pnu.edu.sa (K.M.K.); fmalzahrani@pnu.edu.sa (F.M.A.); benrebahf@yahoo.fr (F.B.R.)

check for updates

Citation: Alsaiari, N.S.; Amari, A.; Katubi, K.M.; Alzahrani, F.M.; Rebah, F.B.; Tahoon, M.A. Innovative Magnetite Based Polymeric Nanocomposite for Simultaneous Removal of Methyl Orange and Hexavalent Chromium from Water. Processes 2021, 9, 576. https:// doi.org/10.3390/pr9040576

Academic Editor: Katherine M E. Stewart

Received: 27 February 2021

Accepted: 24 March 2021

Published: 26 March 2021

Publisher's Note: MDPI stays neutral with regard to jurisdictional claims in published maps and institutional affiliations.

Copyright: (C) 2021 by the authors Licensee MDPI, Basel, Switzerland. This article is an open access article distributed under the terms and conditions of the Creative Commons Attribution (CC BY) license (https:// creativecommons.org/licenses/by/ $4.0 /)$

\begin{abstract}
One of the most important directions for environmental remediation is the effective removal of dyes and toxic heavy metals from water using newly fabricated nanoadsorbents. Here, magnetic $\mathrm{Fe}_{3} \mathrm{O}_{4}$ nanoparticles were combined with nitrogen-containing functional group polymers chitosan (CS) and polypyrrole (ppy) to synthesize a nanocomposite (polypyrrole@magnetic chitosan) useful for removing methyl orange (MO) and hexavalent chromium ( $\mathrm{Cr}(\mathrm{VI})$ ) from water. The physicochemical properties of the nanocomposite were determined using SEM, TEM, XRD, FT-IR, and TGA techniques. The effect of different factors on the adsorption system was studied including the contact time, $\mathrm{pH}$, and the effect of co-existed ions. The kinetic study illustrated that the adsorption fit well with Langmuir isotherm. The maximum adsorption capacity of $\mathrm{MO}$ and $\mathrm{Cr}(\mathrm{VI})$ was found to be 95 and $105 \mathrm{mg} / \mathrm{g}$, respectively. The reusability of the nanocomposite was studied for up to five cycles using $0.1 \mathrm{M} \mathrm{NaOH}$ as eluent with a slight decrease of adsorbent efficiency. Furthermore, the removal mechanism studied suggested the removal of $\mathrm{MO}$ via adsorption and $\mathrm{Cr}$ (VI) via chemical reduction and adsorption. This study suggests that a ppy@magnetic chitosan nanocomposite is a promising nanoadsorbent for removing $\mathrm{MO}$ and $\mathrm{Cr}(\mathrm{VI})$ from water.
\end{abstract}

Keywords: environment; polymers; nanomaterials; water treatment

\section{Introduction}

Environmental degradation and the lack of clean water have become universal problems associated with the fast increase in industrial activity and social economy and should be solved to maintain a high-quality life [1-3]. Recently, great attention has been paid to water treatment for heavy metals $[4,5]$ resulting from steel fabrication, leather tanning, and metal processing and from toxic dyes from the paper, cosmetics, plastics, textile, and food industries. Among these pollutants, the organic dye methyl orange (MO) can cause severe health problems like jaundice, tissue necrosis, tachycardia, vomiting, and cyanosis. Furthermore, as a conventional toxic heavy metal, chromium not only causes significant damage to human health, but also generates extreme environmental contamination that is hard to remediate [6]. Trivalent chromium $\mathrm{Cr}$ (III) and hexavalent chromium $\mathrm{Cr}$ (VI) are the two oxidation states of chromium [7]. $\mathrm{Cr}$ (VI) is carcinogenic and known to be a very 
dangerous contaminant, while $\mathrm{Cr}$ (III) is less toxic to humans and other organisms and is less movable in environmental systems [8]. According to the World Health Organization (WHO), the allowable level of $\mathrm{Cr}$ (VI) in water must not exceed $0.05 \mathrm{mg} / \mathrm{L}$ [9]. However, in wastewater from chromium electroplating, the $\mathrm{Cr}(\mathrm{VI})$ levels were found to reach 100 to $500 \mathrm{mg} / \mathrm{L}$. Thus, the transformation of $\mathrm{Cr}$ (VI) to $\mathrm{Cr}$ (III) via an efficient reduction concept and the efficient adsorption of $\mathrm{MO}$ can greatly decrease the possible hazard of $\mathrm{Cr}(\mathrm{VI})$ and MO dye to animals, humans, and the environment $[10,11]$. Water contamination from chromium and dye has been widely remediated over the past years. In this context, $\mathrm{Cr}$ (VI) and MO have been efficiently removed using various techniques including adsorption, electrochemical methods, reduction, biological remediation, ion exchange, and chemical precipitation [12-15]. Due to its low cost, great efficiency, and simple processing procedures, adsorption is considered the most promising method. Several adsorbents have been proposed for the effective removal of $\mathrm{MO}$ and $\mathrm{Cr}(\mathrm{VI})$ : carbon nanomaterials [16,17], layered double hydroxides [18,19], agricultural waste [16], chitosan [20], metal oxides [21], zeolites [22], and clay minerals [23]. The biocompatibility, nontoxicity, and biodegradability of chitosan make it attractive among other materials for removing of pollutants from water. Chitosan is a polysaccharide with a linear structure resulting from the alkaline treatment of the second-most abundant biopolymer in nature (chitin), which is present in the shells of lobsters, crabs and shrimp [24]. Chitosan is bio-attracted to negatively charged moieties and is water soluble because of an amino group that has a pKa of 6.5, causing it to be easily protonated in a neutral medium and acidic solution. Its molecular structure has large numbers of hydroxyl and amino groups that provide chelation power toward different metal ions [25]. Although adsorption is the most efficient method for $\mathrm{Cr}$ (VI) and MO removal, it is considered to be nondestructive, and the regeneration of the adsorbed materials limits the application of chitosan to treat real wastewater. Additionally, only the phase transition of contaminants can be realized by adsorption alone although their intrinsic essence (physicochemical property and toxicity) remains unchanged. Therefore, the best solution is to fabricate a material that can provide in situ chemical reduction of $\mathrm{Cr}$ (VI) to $\mathrm{Cr}$ (III) (considered less toxic with useful characteristics for organisms) and the simultaneous adsorption of both $\mathrm{MO}$ and $\mathrm{Cr}(\mathrm{VI})$; however, the association of reduction removal with adsorption has rarely been studied. Moreover, the common recovery techniques used for adsorption - centrifugation, sedimentation, and filtration - have several problems, including cost, high energy consumption, and low potency. The continued recycling of chitosan powder may not be easy due to its biodegradability; however, its adsorption ability has been improved using nanotechnology, which allows the incorporation of nanomaterials in the adsorbent materiel providing very small particle size and large surface area. However, these types of nanoadsorbents still suffer from decreased recycling performance and a complex separation process. Lately, as an adsorbent and adsorbent carrier, magnetic nanoparticles have shown exceptional properties such as simple chemical modification, a large specific surface area, and excellent magnetic characteristics and have attracted the attention of environmental engineers [26,27]. However, the lack of functional groups and the agglomeration of magnetic nanoparticles reduce their adsorption of pollutants. Accordingly, the development of a novel recyclable material having a high adsorption ability necessitates combining the benefits of polymer materials and magnetic nanoparticles (NPs). In recent years great attention has definitely been paid to magnetic chitosan nanocomposites constructed with a magnetic core of hematite $\left(\mathrm{Fe}_{3} \mathrm{O}_{4}\right)$ NPs and a chitosan shell [28]. The fast and easy separation of an adsorbent by a commercial magnet as well as excellent mechanical features were provided via the combination of both magnetic NPs and a chitosan biopolymer. Furthermore, the adsorption capacity of magnetic chitosan can be increased by surface modification through the existing amino and hydroxyl groups on its surface. As previously reported, the modification of chitosan with different organic functional moieties (xanthate, $\alpha$-ketoglutaric acid, thiourea, and ethylenediamine) could enhance its adsorption capacity toward different pollutants [29]. The low synthesis cost, biocompatibility, and better environmental stability enhanced the 
application of a polypyrrole (Ppy)-conducting polymer for heavy metal removal from water [30]. Polypyrrole is a polymer with a molecular structure containing high numbers of imine groups that provide adsorption sites toward different dyes and metals. In addition to that, the imine groups provide a reduction capacity to convert $\mathrm{Cr}$ (VI) to $\mathrm{Cr}$ (III). Thus, Ppy can remove hexavalent chromium ions from water via both reduction and adsorption, and remove $\mathrm{MO}$ via adsorption. Based on this information, the in situ chemical reduction of $\mathrm{Cr}(\mathrm{VI})$ and the simultaneous adsorption of both $\mathrm{Cr}(\mathrm{VI})$ and $\mathrm{MO}$ could enhance the adsorption capacity. Interestingly, excellent separation ability could be obtained by fabricating a novel nanocomposite containing the three parts to exploit the advantages offered by each component: (i) reductant and adsorbent ability of polypyrrole; (ii) large number of hydroxyl and amino groups of chitosan; and (iii) magnetic characteristics of hematite nanoparticles $\left(\mathrm{Fe}_{3} \mathrm{O}_{4}\right)$. As far as we know, there is no similar study. In particular, this novel nanocomposite detoxified water of both hexavalent chromium $\mathrm{Cr}$ (VI) and MO. Herein, the novel nanocomposite was synthesized via the combination of $\mathrm{CS}, \mathrm{Fe}_{3} \mathrm{O}_{4} \mathrm{NPs}$, and polypyrrole. First, a one-step co-precipitation method was used to synthesize magnetic chitosan by mixing two oxidation states of iron with chitosan followed by the modification of magnetic chitosan with polypyrrole using oxidative polymerization to produce the nanocomposite ppy@CS $/ \mathrm{Fe}_{3} \mathrm{O}_{4}$. This nanocomposite was tested to remove $\mathrm{MO}$ and $\mathrm{Cr}$ (VI) from water. The chemical composition, surface structure, and morphology of synthesized ppy@CS $/ \mathrm{Fe}_{3} \mathrm{O}_{4}$ were characterized via XRD, FT-IR, SEM, and TEM. In order to understand the removal mechanism, the effect of different factors on adsorption behavior (contact time, initial concentration, and $\mathrm{pH}$ ) was studied. Lastly, the ppy@CS $/ \mathrm{Fe}_{3} \mathrm{O}_{4}$ nanocomposite was found to remove $\mathrm{Cr}(\mathrm{VI})$ via in situ chemical reduction and adsorption while MO was also adsorbed. This nanocomposite was found to be very promising for removing metals and dyes from water as shown by its recyclability and the stability of the obtained data.

\section{Materials and Methods}

\subsection{Chemicals}

Chitosan was used as received (Winlab Company, Leicester, UK, molecular weight $=100,000-300,000)$ while polypyrrole and pyrrole $(98.0 \%)$ were supplied from SigmaAldrich (St. Louis, MO, USA). Sodium sulfate $(99.0 \%)$, sodium chloride $(99.9 \%)$, sodium bicarbonate $(99.0 \%)$, hydrochloric acid $(35.0 \%)$, sodium hydroxide pellets $(97.0 \%)$, methyl orange $(95.0 \%)$ and potassium dichromate $(99.9 \%)$ were supplied from CDH chemicals (New Delhi, India), while ammonium persulfate, ferrous sulfate heptahydrate, and ferric chloride hexahydrate were supplied from Sinopharm Chemical Reagent Co., Ltd (Shanghai, China). All chemicals were of analytical grade and used without any additional purifications. Distilled water was used for the preparation of all experimental solutions.

\subsection{Polypyrrole Magnetic Chitosan Synthesis}

Firstly, the magnetic chitosan was prepared via the co-precipitation method as described in our previous work [31]. Briefly, two oxidation states of iron $\left(\mathrm{FeCl}_{3}\right.$ and $\mathrm{FeSO}_{4}$ solutions) were mixed in a conical flask in 2:1 molar ratios, respectively, followed by the dropwise addition of aqueous ammonia $(33 \%, v / v)$ accompanied by vigorous stirring under a nitrogen atmosphere for $30 \mathrm{~min}$. After that, the nanoparticles were washed four times with distilled $\mathrm{H}_{2} \mathrm{O}$ and collected with a permanent magnet. Then, a reverse-phase suspension method was used for the synthesis of magnetic chitosan in which a mixture of $0.6 \mathrm{~mL}$ of tween $80,54 \mathrm{~mL}$ of mineral oil, and $200 \mathrm{mg}$ of synthesized $\mathrm{Fe}_{3} \mathrm{O}_{4} \mathrm{NPs}$ ) was supplemented with $1 \%(w / v)$ of chitosan dissolved in an acetic acid solution. For $40 \mathrm{~min}$, the resulting magnetic chitosan was stirred and sonicated followed by the addition of $(4 \mathrm{~mL}, 25 \% w / v)$ glutaraldehyde. Stirring continued up to $5 \mathrm{~h}$. Then, a permanent magnet was used to separate the synthesized magnetic chitosan, which was washed several times with acetone followed by drying at $45^{\circ} \mathrm{C}$ in a vacuum. Secondly, the synthesized magnetic chitosan was modified using pyrrole monomers according the oxidative polymerization method, and $0.6 \mathrm{~g}$ of magnetic chitosan was added to $100 \mathrm{~mL}$ of water. Then, $2.5 \mathrm{~mL}$ 
of pyrrole was added to the previous mixture followed by the addition of $(5.0 \mathrm{~mL}, 1 \mathrm{M})$ $\mathrm{HCl}$ solution. For $30 \mathrm{~min}$, this mixture was stirred in an ice bath. An aqueous solution of ammonium persulfate ( $4 \mathrm{~g}$ in $20 \mathrm{~mL}$ ) as initiator, was added to the mixture and stirred vigorously for four hours in an ice bath. Then, to $100 \mathrm{~mL}$ aqueous ammonia $(33 \%, v / v)$ the recovered nanoparticles were added under continuous stirring for $13 \mathrm{~h}$. Then, the product was washed several times with distilled water and ethyl alcohol followed by separation with a magnet and dried for $13 \mathrm{~h}$ at $75^{\circ} \mathrm{C}$.

\subsection{Nanocomposite Characterization}

The synthesized ppy@magnetic chitosan nanocomposite was characterized using different instruments including a UV/vis spectrometer, Raman spectrometer, magnetometer, thermogravimetric analysis (TGA) measurement, Fourier transform infrared (FT-IR) spectrophotometer, X-ray diffraction (XRD), scanning electron microscope (SEM), and transmission electron microscope (TEM). A UV spectrometer (UVD-2960, Labomed Inc., Los Angeles, CA, USA) was used to measure UV-visible absorption spectra. A triple Raman spectrometer (Horiba, Horiba Inc., Ann Arbor, MI, USA) was used to measure Raman spectra. A vibrating sample magnetometer (Lake Shore 7410, Lake Shore Cryotronics Inc., Westerville, $\mathrm{OH}, \mathrm{USA}$ ) was used to measure the magnetization of the nanocomposite. A Perkin Elmer, STA 6000 (PerkinElmer Inc., Shelton, CT, USA) was used to perform the thermogravimetric analysis in the temperature range of $30-800{ }^{\circ} \mathrm{C}$ with $30{ }^{\circ} \mathrm{C} \mathrm{min}-1$ of heating rate under a nitrogen atmosphere. A Bruker, Tensor 27 FT-IR (Karlsruhe, Germany) spectrophotometer was used to perform FT-IR spectra in the range of $400-4000 \mathrm{~cm}^{-1}$ at room temperature and collected at a resolution of $4 \mathrm{~cm}^{-1}$. A GNR APD-2000 PRO (GNR, Cairo, Egypt) diffractometer was used to measure XRD using $\mathrm{Cu}$ Ka radiation $(\lambda=1.5406 \AA)$ operated at $45 \mathrm{kV}$. The diffraction intensities were recorded over the $2 \theta$ ranging from 5 to $90^{\circ}$ with the constant scanning rate of $1^{\circ} \cdot \mathrm{min}^{-1}$. A TEM (JEM-2100F, Hillsboro, OR, USA) operating at $200 \mathrm{kV}$ and a SEM (Hitachi S4800, Hitachi, Tokyo, Japan) were used, respectively, to study the size and morphology of the nanocomposite.

\subsection{Adsorption Batch Experiments}

A stock solution $(1.0 \mathrm{~g} / \mathrm{L})$ of $\mathrm{MO}$ and dichromate salt $\left(\mathrm{K}_{2} \mathrm{Cr}_{2} \mathrm{O}_{7}\right)$ were prepared in distilled water and used for further dilution. For the study of the effectiveness of ppy@magnetic chitosan for removing MO and $\mathrm{Cr}(\mathrm{VI})$, adsorbent experiments were conducted in batch mode using $100 \mathrm{~mL}$ bottles. In each batch, $100 \mathrm{mg}$ of the adsorbent (ppy@magnetic chitosan) was added to $50 \mathrm{~mL}$ of the pollutant solution $(100 \mathrm{mg} / \mathrm{L})$. The $\mathrm{pH}$ was adjusted using $1.0 \mathrm{M}$ of $\mathrm{HCl}$ and $1.0 \mathrm{M}$ of $\mathrm{NaOH}$. Then, the samples were incubated under shaking $\left(200 \mathrm{rpm}\right.$ at $\left.25^{\circ} \mathrm{C}\right)$ using a thermostated shaker. A permanent magnet was used to recover the adsorbent at certain intervals. The remaining supernatant was analyzed for $\mathrm{MO}$ and $\mathrm{Cr}(\mathrm{VI})$ residual concentrations using a UV-Vis spectrophotometer at $\lambda_{\max }$ of 465 and $541 \mathrm{~nm}$, respectively. The effect of different parameters on adsorption performance ( $\mathrm{pH}$, contact times, and competing ions $\mathrm{Cl}^{-}, \mathrm{HCO}_{3}{ }^{-}$, and $\mathrm{SO}_{4}{ }^{2-}$ ) was studied. The recyclability of the adsorbent was also studied by immersing it after the experiment in $1.0 \mathrm{M} \mathrm{NaOH}$ as eluent (for one hour) then shaking it for $13 \mathrm{~h}$. To examine the ppy@magnetic chitosan stability, the recovered adsorbent (with a magnet) was washed with water and ethyl alcohol four times, and then vacuum dried at $75^{\circ} \mathrm{C}$ for 1 day. All adsorption experiments were performed in triplicate. The removal percentage (\%) and adsorption capacity $(\mathrm{mg} / \mathrm{g})$ were determined according to the following equation:

$$
\text { Adsorption capacity }(\mathrm{mg} / \mathrm{g})=\left(\left(\mathrm{C}_{\mathrm{i}}-\mathrm{C}_{\mathrm{t}}\right) / \mathrm{m}\right) \times \mathrm{V}
$$

Each symbol of the above two equations has a well-known meaning. $\mathrm{V}$ denotes the volume of solution, $m$ denotes the mass of ppy@magnetic chitosan, and $C_{i}$ and $C_{t}$ represent the initial and final concentration of $\mathrm{MO}$ and $\mathrm{Cr}(\mathrm{VI})$ pollutants, respectively. 


\section{Results and Discussions \\ 3.1. Nanocomposite Characterization}

The morphology, size, and shape of synthesized magnetic chitosan and ppy@magnetic chitosan were characterized using SEM and TEM images as shown in Figure 1. According to Figure 1a, the SEM image of magnetic chitosan indicated the presence of abundant pores with rough surfaces. The surfaces of the material showed the presence of several spherical particles of about $26 \mathrm{~nm}$ that represent the magnetite nanoparticles $\left(\mathrm{Fe}_{3} \mathrm{O}_{4}\right)$, thus signifying their effective construction in the fabricated composite.

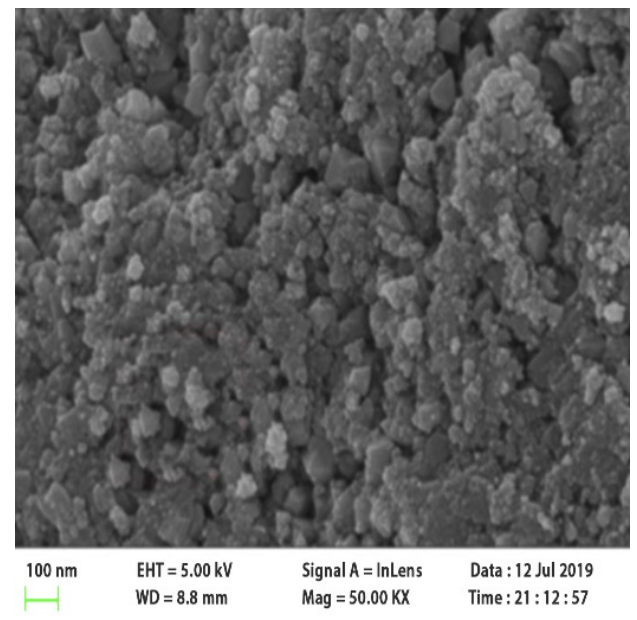

(a)

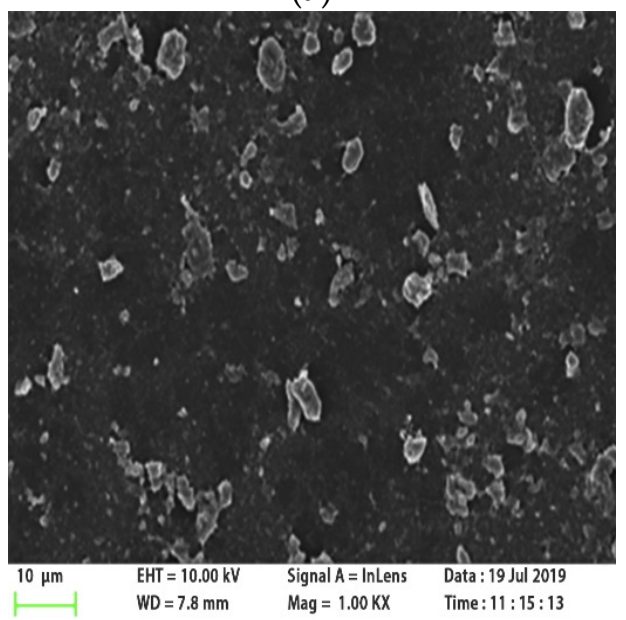

(c)

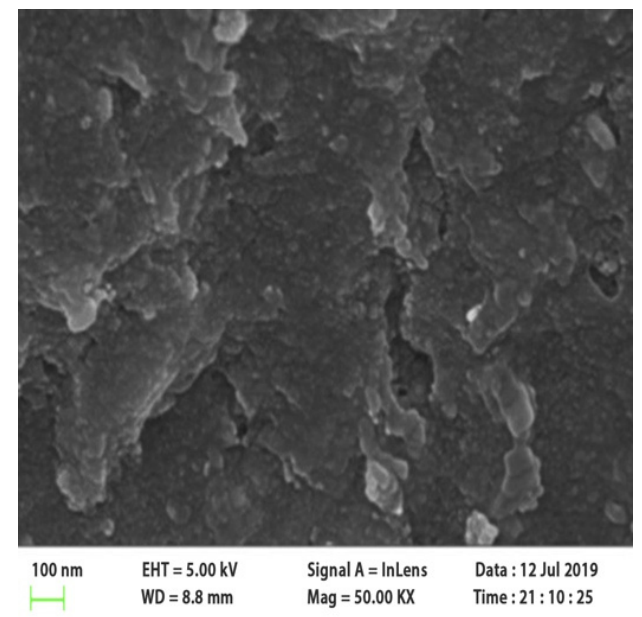

(b)

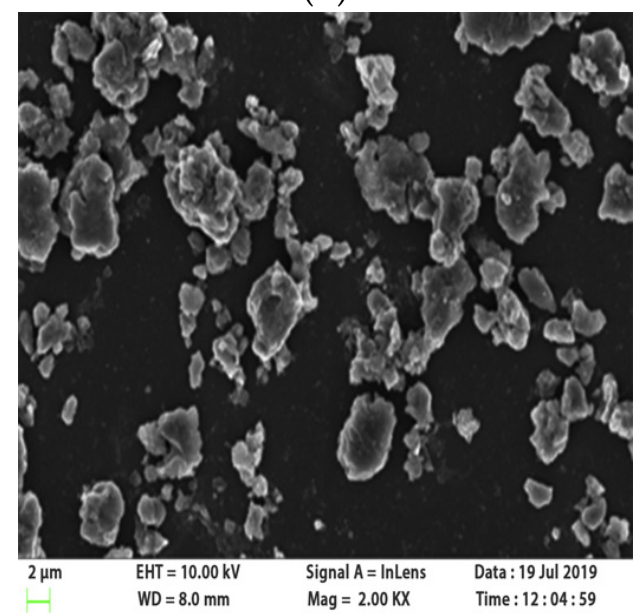

(d)

Figure 1. SEM image of (a) magnetic chitosan and (b) ppy@magnetic chitosan; TEM image of (c) magnetic chitosan and (d) ppy@magnetic chitosan (EHT: electron high tension, WD: working distance).

As observed, there was no clear aggregation phenomenon to indicate the excellent distribution of magnetite nanoparticles over the surface of composite. According to Figure 1b, the ppy loading over magnetic chitosan for the synthesis of the ppy@magnetic chitosan nanocomposite provided a smoother surface compared to that of magnetic chitosan. Polypyrrole was successfully loaded over the magnetic chitosan, which clearly indicated the presence of coated $\mathrm{Fe}_{3} \mathrm{O}_{4}$ nanoparticles, which were mainly implanted between the chitosan and polypyrrole (in the interior of the formed ppy@magnetic chitosan nanocomposite). According to Figure 1c,d, the ppy@magnetic chitosan nanocomposite and magnetic chitosan showed granular and irregular particles, respectively, with a size of $1.00-10.00 \mu \mathrm{m}$ 
Polypyrrole, chitosan, and polypyrrole @magnetic chitosan nanocomposite XRD are shown in Figure 2a. Data for chitosan and polypyrrole were used for comparison. The amorphous structure of ppy was indicated from the wide peak observed at $2 \theta=22.85$ [32] The two peaks of chitosan at $2 \theta=20.35$ and 9.95 are characteristic of the biopolymer chitosan. The definite regularity in the chitosan structure was attributed to the strong intrainter-molecular hydrogen bonds formed by the plentiful amount of amino and hydroxyl groups in the chitosan structure [33]. Many diffraction peaks were present in the XRD of ppy@magnetic chitosan nanocomposite (as shown in Figure 2a) representing the planes (533), (620), (440), (511), (422), (400), (311), (220), and (111) of crystalline magnetite [34-36]. The small crystalline size of magnetite nanoparticles is indicated by very wide peaks compared to the bulk one. Using the Scherrer equation, the average crystalline size of the magnetite nanoparticles was found to be $10 \mathrm{~nm}$ by selecting the highest peaks for calculation. FT-IR spectroscopy was further used to characterize the synthesized ppy@magnetic chitosan nanocomposite as shown in Figure 2b. The broad peak of ppy@magnetic chitosan nanocomposite at $3357 \mathrm{~cm}^{-1}$ corresponds to the chitosan $\mathrm{O}-\mathrm{H}$ axial stretching vibration band $\left(3435 \mathrm{~cm}^{-1}\right)$ and ppy $\mathrm{N}-\mathrm{H}$ stretching vibration band $\left(3450 \mathrm{~cm}^{-1}\right)$, which are shifted in the spectrum of the nanocomposite. Also, the shift of the ppy peak at $1548 \mathrm{~cm}^{-1}$ to $1559 \mathrm{~cm}^{-1}$ in the synthesized nanocomposite as well as the disappearance of the chitosan peak at $1645 \mathrm{~cm}^{-1}$ indicated the strong interaction of both chitosan and ppy with the magnetite nanoparticles. The peaks at 1465 and $1559 \mathrm{~cm}^{-1}$ indicated the strong interaction and coating of chitosan and polypyrrole over the magnetite nanoparticles. The appearance of the new band at $571 \mathrm{~cm}^{-1}$ indicates the presence of magnetite as this band is characteristic of magnetite. The strong electrostatic interaction between $\mathrm{NH}_{4}{ }^{+}$groups in both polymers (chitosan and ppy) and the negatively charged magnetite surface was indicated from the shift of the Fe-O bond peak at 581 and $585 \mathrm{~cm}^{-1}$, which is characteristic of magnetite $\left(571 \mathrm{~cm}^{-1}\right)$. FT-IR results indicate the good integration of chitosan, ppy, and $\mathrm{Fe}_{3} \mathrm{O}_{4}$ nanoparticles in the fabricated ppy@magnetic chitosan nanocomposite.

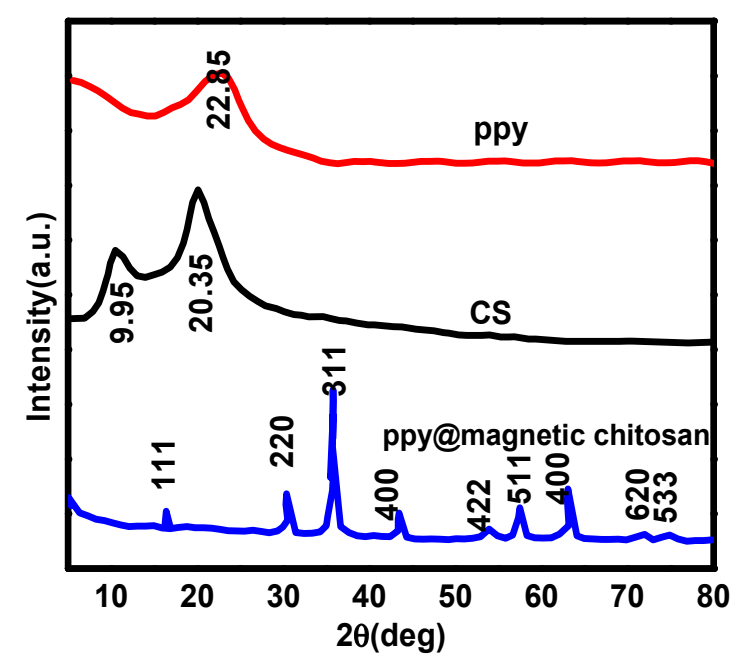

(a)

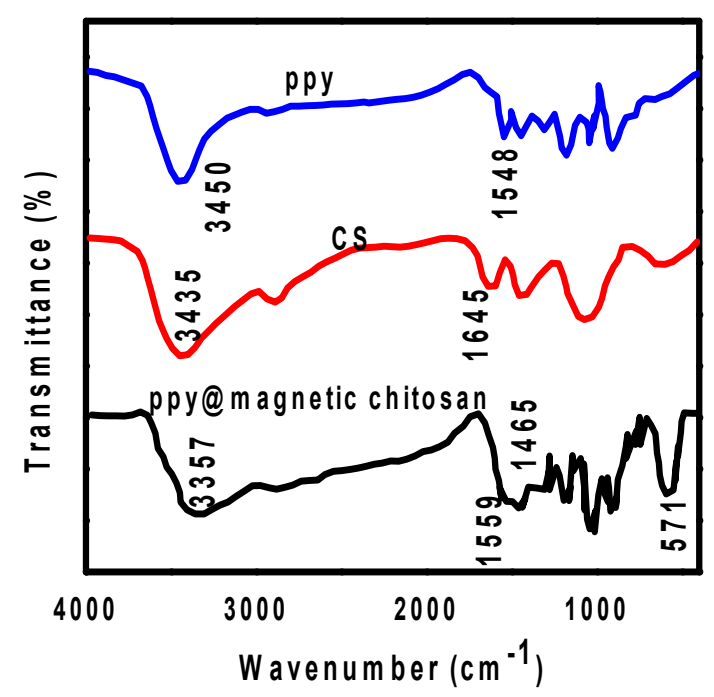

(b)

Figure 2. (a) XRD and (b) FT-IR of polypyrrole (ppy), chitosan (CS), and polypyrrole@magnetic chitosan nanocomposite (ppy@magnetic chitosan).

Raman spectroscopy was used to confirm integration among the three components of the nanocomposite as shown in Figure 3a. The observed two bands at 450 and $625 \mathrm{~cm}^{-1}$ are characteristic of $\mathrm{Fe}_{3} \mathrm{O}_{4}$ and were shifted from 533 and $669 \mathrm{~cm}^{-1}$, respectively. 


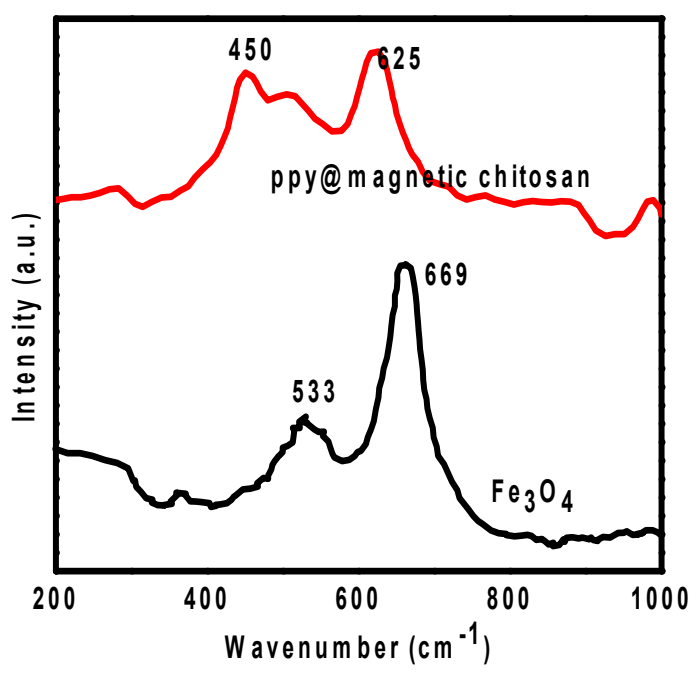

(a)

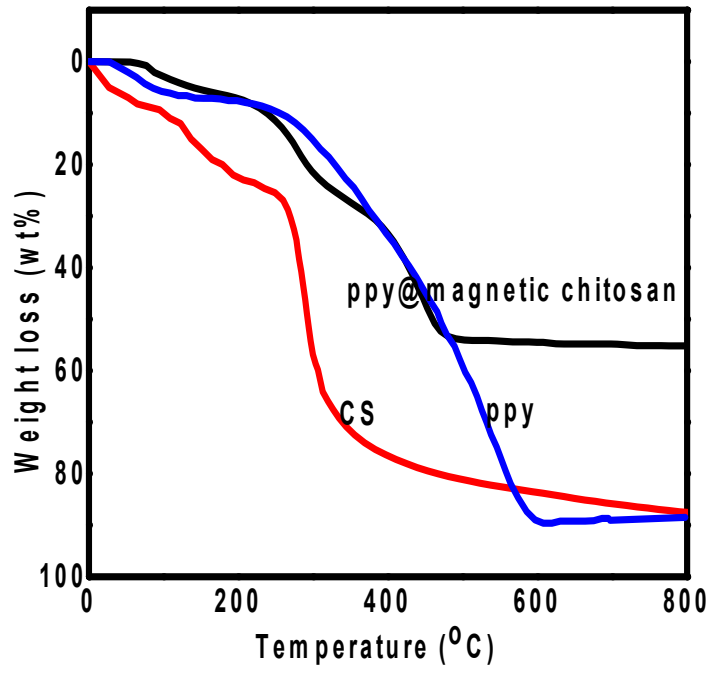

(b)

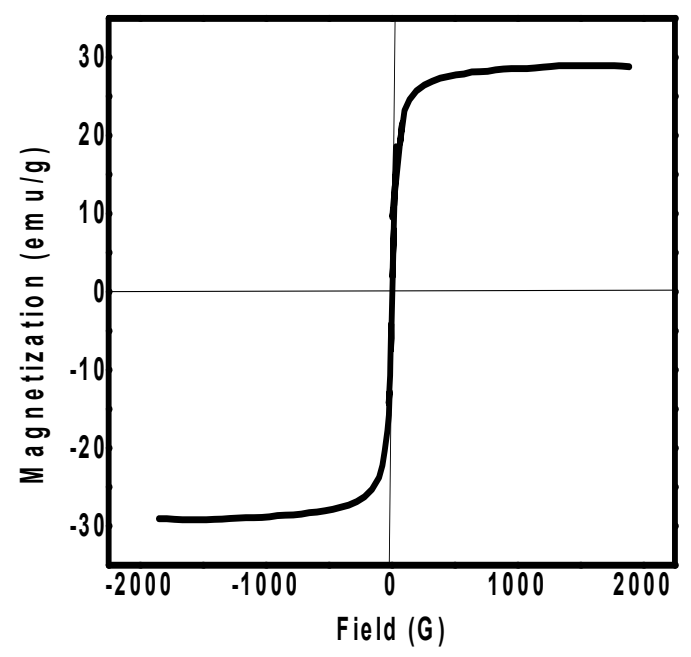

(c)

Figure 3. (a) Raman spectrum, (b) Thermogravimetric analysis, and (c) room temperature magnetization curve of polypyrrole@magnetic chitosan nanocomposite.

This Raman shift was an additional indicator of the strong interaction between the functional groups of chitosan and ppy polymers with the surface of $\mathrm{Fe}_{3} \mathrm{O}_{4}$ nanoparticles. For further data about the synthesized nanocomposite, the TGA investigation was achieved under $\mathrm{N}_{2}$ atmosphere to obtain the thermal properties of the polypyrrole@magnetic chitosan nanocomposite as shown in Figure 3b, which shows three weight loss steps. Firstly, the weight loss between 41 and $166^{\circ} \mathrm{C}$ corresponds to moisture loss from the polymer ppy. Secondly, the weight loss between 166 and $318^{\circ} \mathrm{C}$ corresponds to the chitosan degradation. The last weight loss, between 318 and $489^{\circ} \mathrm{C}$, corresponds to the ppy main-chain degradation. One of the main advantages of the synthesized polypyrrole@magnetic chitosan nanocomposite is its simple separation from the medium by using a magnet. The magnetic properties of the nanocomposite were studied and provided in Figure 3c, which shows the relation between the applied field at room temperature and the magnetization of the studied nanocomposite. According to the magnetization curve, the lack of a hysteresis loop $\left(\mathrm{H}_{\mathrm{C}}\right.$ equal 0) indicates a superparamagnetic nature with no permanent magnetic moment. The high magnetic saturation moment $\left(\mathrm{M}_{\mathrm{S}}\right)$ of polypyrrole@magnetic chitosan nanocomposite 
(equal to $28.99 \mathrm{emu} / \mathrm{g}$ ) was attributed to the magnetic $\mathrm{Fe}_{3} \mathrm{O}_{4}$ great loading. Due to its simple separation from medium solutions using external magnet, the superparamagnetic nanocomposite has attracted great attention for its application in water treatment All the above characterization results approved the good integration and construction among the three parts of the polypyrrole@magnetic chitosan nanocomposite.

\section{2. $p H$ Effect on the Adsorption}

The adsorbent active binding sites and surface chemistry are greatly influenced by the $\mathrm{pH}$, which affects adsorption efficiency. Herein, we study the $\mathrm{pH}$ effect on $\mathrm{MO}$, and $\mathrm{Cr}$ (VI) adsorption using polypyrrole@magnetic chitosan nanocomposite over a wide pH range from 2 to 12. Figure 4 a illustrates the results. \%clearpage

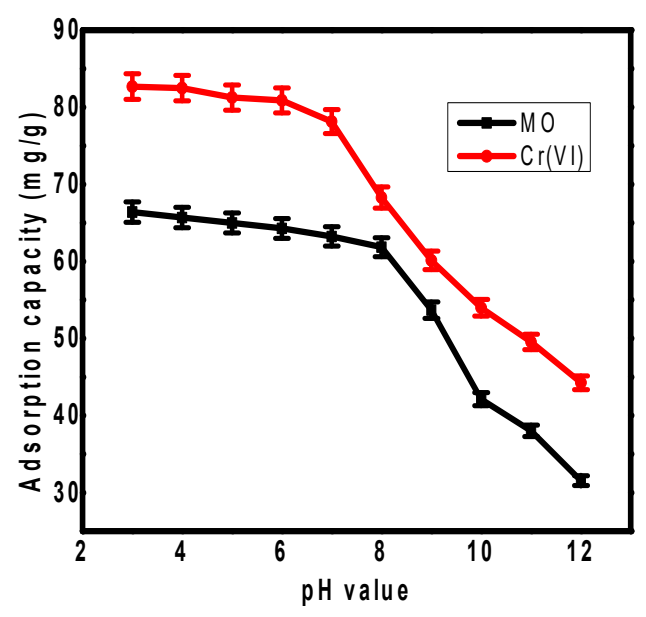

(a)

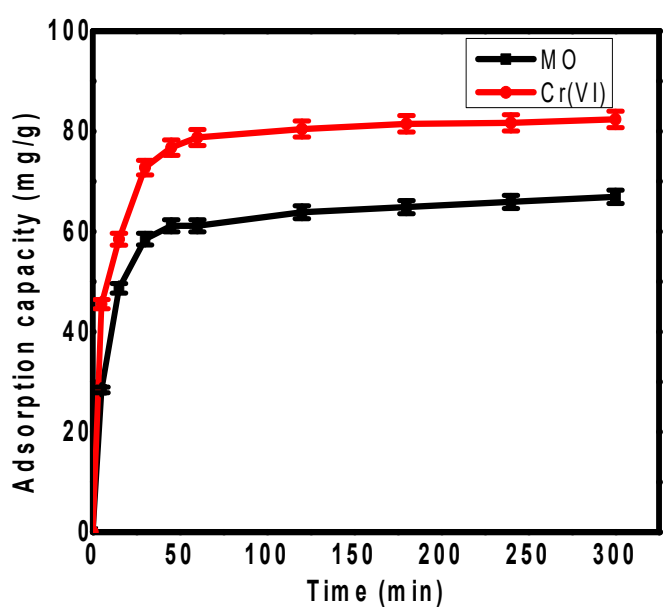

(b)

Figure 4. The effect of (a) pH value and (b) the contact time on the adsorption of $\mathrm{MO}$ and $\mathrm{Cr}(\mathrm{VI})$ over polypyrrole@magnetic chitosan nanocomposite.

The adsorption investigations to study the $\mathrm{pH}$ effect were performed at $25{ }^{\circ} \mathrm{C}$ with a contact time of $40 \mathrm{~min}$, adsorbent dosage of $100 \mathrm{mg}$, initial concentration of both pollutants of $100 \mathrm{mg} / \mathrm{L}$, and shaking rate of $200 \mathrm{rpm}$. The results showed that the removal of both $\mathrm{Cr}(\mathrm{VI})$ and $\mathrm{MO}$ are $\mathrm{pH}$ dependent. The $\mathrm{pH}$ increase led to a decrease in $\mathrm{MO}$ and $\mathrm{Cr}$ (VI) removal capacity due to the strong electrostatic interaction between the adsorbent positive charge at low $\mathrm{pH}$ and pollutants negative charge [37]. Additionally, at $\mathrm{pH}$ below 4.5, a high $\mathrm{MO}$ concentration could precipitate [38]. For $\mathrm{Cr}(\mathrm{VI}), \mathrm{HCrO}_{4}{ }^{-}$is the dominant anion at $\mathrm{pH}$ lower than 6 while at $\mathrm{pH}$ higher than 6 the dominant form is $\mathrm{CrO}_{2}{ }^{4-}$ that cause electrostatic repulsion between different ions. Thus, at high $\mathrm{pH}$ the major reason for the decreased adsorption efficiency of $\mathrm{MO}$ and $\mathrm{Cr}$ (VI) was electrostatic repulsion. Consequently, the removal of $\mathrm{MO}$ and $\mathrm{Cr}$ (VI) over a polypyrrole@magnetic chitosan nanocomposite is very suitable in a neutral or acidic medium at an optimal $\mathrm{pH}$ value between 2 and 4.5. This behavior concerning the removal of both pollutants at different $\mathrm{pH}$ values is similar to another study reported in the literature [39].

\subsection{Contact Time Effect on the Adsorption}

The adsorption of $\mathrm{MO}$ and $\mathrm{Cr}(\mathrm{VI})$ over polypyrrole@magnetic chitosan nanocomposite was performed at different reaction times ranging from 0 to $300 \mathrm{~m}$ as shown in Figure $4 \mathrm{~b}$. The adsorption investigations to study the contact-time effect were performed at $25^{\circ} \mathrm{C}, \mathrm{pH} 4.5$, agitation speed $200 \mathrm{rpm}$, and adsorbent dosage $100 \mathrm{mg}$ with initial pollutant concentrations of $100 \mathrm{mg} / \mathrm{L}$. During the initial stage as shown in Figure $4 \mathrm{~b}$, there was rapid adsorption efficiency of MO and $\mathrm{Cr}$ (VI). The synergistic effects between adsorbate and adsorbent in the aqueous solution were responsible for a clear high adsorption efficiency. 
This stage is the saturation phase in which all possible adsorption sites are saturated with the pollutants. In the case of the present adsorbent, saturation was achieved after $40 \mathrm{~min}$ due the interaction between adsorbent surface sites and the adsorbate ions. After the saturation phase, there was no substantial change. Thus, the adsorption of $\mathrm{MO}$ and $\mathrm{Cr}(\mathrm{VI})$ over the nanoadsorbent polypyrrole@magnetic chitosan is related to the physicochemical interactions between the adsorbate and adsorbent in water. Particle diffusion and mass transfer indicate that this system is chemically rate controlled.

\subsection{Competitive Ions Effect}

The selectivity of any promising adsorbent must be studied for different competing co-ions. Therefore, we studied the adsorption efficiency of polypyrrole@magnetic chitosan nanocomposite toward $\mathrm{Cr}(\mathrm{VI})$ and $\mathrm{MO}$ in the presence of bicarbonate, sulfate, and chloride co-ions, which may be present in drinking water (Figure 5a). These co-existing ions usually competed with the pollutants on the adsorption active sites over the polypyrrole@magnetic chitosan nanocomposite surface. To study the effect of co-ions, the adsorption experiment was performed at $25^{\circ} \mathrm{C}, \mathrm{pH} 4.5$, agitation speed $200 \mathrm{rpm}$, contact time $40 \mathrm{~m}$, and adsorbent dose $100 \mathrm{mg}$, with co-ion concentrations of $200 \mathrm{mg} / \mathrm{L}$.

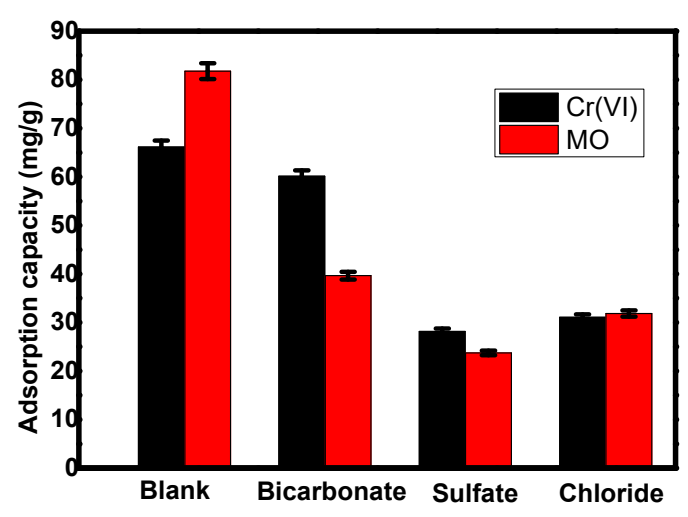

(a)

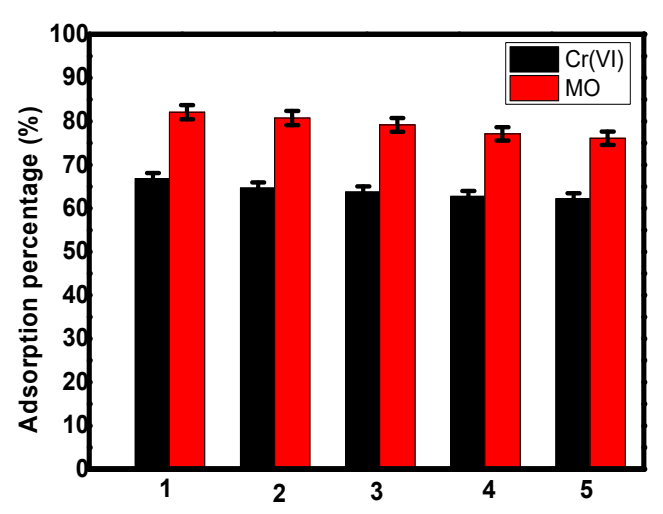

(b)

Figure 5. (a) Competitive ions effect on $\mathrm{Cr}(\mathrm{VI})$ and MO adsorption over polypyrrole@magnetic chitosan, and (b) reusability study of the nanocomposite toward $\mathrm{Cr}(\mathrm{VI})$ and $\mathrm{MO}$ adsorption from water.

According to Figure 5a, among the tested ions, sulphate showed the greatest effect for adsorption efficiency. This may be related to the higher affinity of the adsorbent amino group for $\mathrm{SO}_{4}{ }^{2-}$, which has higher electronic charge. On the other hand, chloride allowed an important reduction in the removal efficiency of both $\mathrm{MO}$ and $\mathrm{Cr}$ (VI). This may be attributed to their greater negative density charge compared to other negative ions. The similarity of ionic charge between $\mathrm{Cr}(\mathrm{VI})$ and bicarbonate ions had a greatly competitive effect on $\mathrm{Cr}(\mathrm{VI})$ adsorption [40]. In contrast, $\mathrm{MO}$ adsorption was not significantly affected by the bicarbonate ions.

\subsection{Reusability of the Adsorbent}

Reusability of any adsorbent is the main factor determining its economic feasibility for application in real water treatment. In order to study the reusability of polypyrrole@magnetic chitosan nanocomposite for the removal of both $\mathrm{MO}$ and $\mathrm{Cr}(\mathrm{VI}), 5$ successive cycles were performed using adsorbent dose of $100 \mathrm{mg}$ in an adsorption-desorption experiment as shown in Figure $5 \mathrm{~b}$. During the desorption process, we applied $0.1 \mathrm{M}$ sodium hydroxide as eluent. According to the Figure $5 b$, there was a little decrease in removal efficacy after each cycle. This decrease was attributed to the damage of the polypyrrole@magnetic chitosan nanocomposite reactive groups on the surface as well as to the loss of its integrity. Consequently, the excellent polypyrrole@magnetic chitosan nanocomposite 
performance and reusability was approved for water treatment of $\mathrm{MO}$ and $\mathrm{Cr}$ (VI) after 5 regeneration cycles.

\subsection{Adsorption Isotherm}

The adsorption isotherm experiments were done to calculate the maximum adsorption efficiency of a polypyrrole@magnetic chitosan nanocomposite on $\mathrm{MO}$ and $\mathrm{Cr}(\mathrm{VI})$. The experiments were performed at $25^{\circ} \mathrm{C}, \mathrm{pH} 5.4$, agitation speed $200 \mathrm{rpm}$, and adsorbent dosage $100 \mathrm{mg}$ with initial MO and $\mathrm{Cr}$ (VI) concentrations ranging from 20 to $200 \mathrm{mg} / \mathrm{L}$. Freundlich and Langmuir isotherms were used to study the relation between the initial concentration and the adsorption isotherm according to the following two equations, respectively.

$$
\begin{aligned}
& C_{e} / q_{e}=\left(1 / q_{m}^{b}\right)+\left(C_{e} / q_{m}\right), \\
& \log q_{e}=\log K_{F}+1 / n\left(\log C_{e}\right),
\end{aligned}
$$

where $\mathrm{n}$ and $\mathrm{K}_{\mathrm{F}}$ are isotherm constants of the adsorption efficacy; $\mathrm{b}$ is the equilibrium constant; and $\mathrm{q}_{\mathrm{m}}$ denotes maximum $\mathrm{MO}$ and $\mathrm{Cr}(\mathrm{VI})$ adsorption. Isotherm parameters here were calculated using Langmuir and Freundlich isotherms and tabulated in Table 1. The results are shown in Figure 6.

Table 1. Freundlich and Langmuir isotherm parameters for the removal of $\mathrm{MO}$ and $\mathrm{Cr}(\mathrm{VI})$ using polypyrrole@magnetic

\begin{tabular}{|c|c|c|c|c|c|c|c|c|c|}
\hline \multirow[t]{2}{*}{ Pollutant } & \multicolumn{5}{|c|}{ Freundlich } & \multicolumn{4}{|c|}{ Langmuir } \\
\hline & $\begin{array}{c}\mathrm{qe}_{\mathrm{e}} \\
(\mathrm{mg} / \mathrm{g})\end{array}$ & $\underset{(\mathrm{mg} / \mathrm{g})}{\mathrm{q}_{\mathrm{m}}}$ & $\begin{array}{c}\mathrm{K}_{\mathrm{F}} \\
(\mathrm{L} \cdot \mathrm{mg} / \mathrm{g})\end{array}$ & $\mathbf{n}$ & $\mathbf{R}^{2}$ & $\mathrm{q}_{\mathrm{e}}(\mathrm{mg} / \mathrm{g})$ & $\underset{(\mathrm{mg} / \mathrm{g})}{\mathrm{qm}_{\mathrm{m}}}$ & $\begin{array}{c}\mathrm{K}_{\mathrm{L}} \\
(\mathrm{L} \cdot \mathrm{mg} / \mathrm{g})\end{array}$ & $\mathbf{R}^{2}$ \\
\hline $\mathrm{MO}$ & 88.8 & 97.9 & 46.9 & 4.789 & 0.880 & 94.9 & 97.9 & 0.323 & 0.998 \\
\hline $\mathrm{Cr}(\mathrm{VI})$ & 101.5 & 106.4 & 32.7 & 4.679 & 0.847 & 104.8 & 106.4 & 0.268 & 0.997 \\
\hline
\end{tabular}
chitosan nanocomposite.

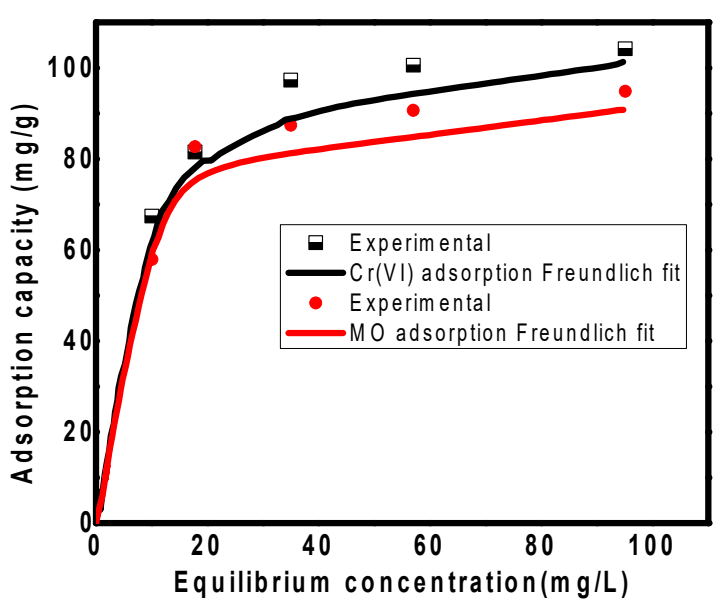

(a)

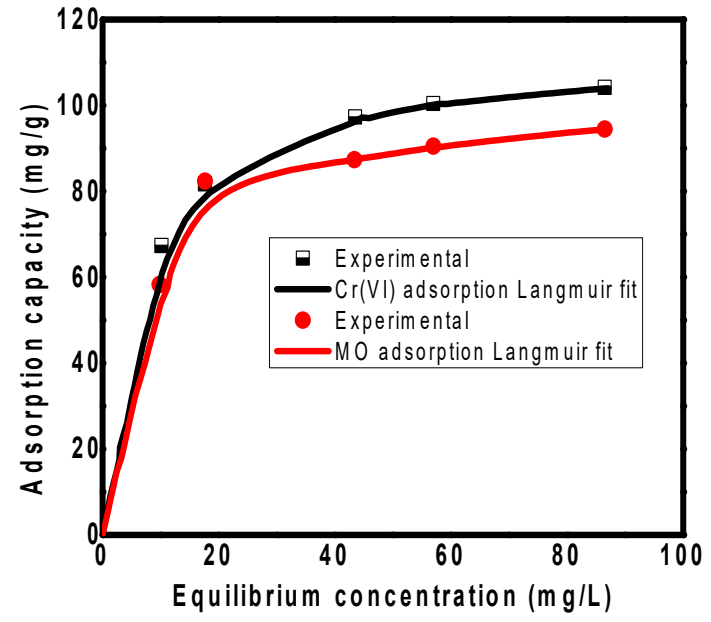

(b)

Figure 6. (a) Freundlich isotherm, and (b) Langmuir isotherm for the removal of $\mathrm{MO}$ and $\mathrm{Cr}(\mathrm{VI})$ over polypyrrole@magnetic chitosan nanocomposite.

Homogeneous adsorption sites and monolayer interaction between the nanocomposite surface and adsorbates $(\mathrm{MO}, \mathrm{Cr}(\mathrm{VI}))$ were confirmed from the regression coefficient $\left(\mathrm{R}^{2}\right)$, which indicated that the Langmuir isotherm was more fit than the Freundlich isotherm as shown in Table 1. This was an indication of the behavior of the nanocomposite adsorption monolayer besides active sites homogeneity. Also, it showed that the different active sites on the nanocomposite surface have energetically equivalent properties. According to this, the chemical bonds between the adsorbent and adsorbates primarily showed monolayer 
adsorption over the studied nanoadsorbent with no additional interaction between the adsorbed pollutant molecules and other pollutants. Interestingly, the $\mathrm{MO}$ and $\mathrm{Cr}$ (VI) maximum removal capacity over the polypyrrole@magnetic chitosan nanocomposite was found to be 95 and $105 \mathrm{mg} / \mathrm{g}$, respectively, which is higher than previous reported studies as tabulated in Table 2.

Table 2. The comparison between the removal of $\mathrm{MO}$ and $\mathrm{Cr}$ (VI) over polypyrrole@magnetic chitosan nanocomposite and previous studies.

\begin{tabular}{|c|c|c|c|c|}
\hline \multirow{2}{*}{ Adsorbent } & \multirow{2}{*}{ Operating Conditions } & \multicolumn{2}{|c|}{ Removal Efficiency (mg/g) } & \multirow{2}{*}{ Ref. } \\
\hline & & MO & $\mathrm{Cr}(\mathrm{VI})$ & \\
\hline ppy@magnetic chitosan & $\begin{aligned} \text { dosage: } & 100 \mathrm{mg} / \mathrm{L} \text {, contact time: } 40 \mathrm{~min} \text {, } \\
& 25^{\circ} \mathrm{C} ; 200 \mathrm{rpm}, \mathrm{pH} 4.5\end{aligned}$ & 95 & 105 & This study \\
\hline Magnetic biochar & $\begin{array}{l}\text { dosage: } 200 \mathrm{mg} / \mathrm{L} \text {; contact time: } 5 \text { days, } \\
25^{\circ} \mathrm{C}, 160 \mathrm{rpm} \text {, pH } 5\end{array}$ & - & 77.54 & {$[41]$} \\
\hline Chitosan/diatomite composite & $\begin{array}{c}\text { dosage: } 0.2 \mathrm{~g} / \mathrm{L} \text {, contact time: } 40 \mathrm{~min} \text {, } \\
25^{\circ} \mathrm{C}, \mathrm{pH} 5\end{array}$ & 35 & - & {$[42]$} \\
\hline $\begin{array}{l}\text { CuO NPs } \\
\text { Graphene oxide }\end{array}$ & $\begin{array}{l}\text { dosage: } 25 \mathrm{mg} / \mathrm{L} \text {, contact time: } 100 \mathrm{~min} \text {, } \\
25-40{ }^{\circ} \mathrm{C}, \mathrm{pH} 3\end{array}$ & - & 16.83 & [37] \\
\hline Banana peel & $\begin{array}{l}\text { dosage: } 100 \mathrm{mg} / \mathrm{L} \text {, contact time: } 24 \mathrm{~h} \text {, } \\
30^{\circ} \mathrm{C}, 180 \mathrm{rpm}, \mathrm{pH} 6-7\end{array}$ & 21 & - & [43] \\
\hline $\begin{array}{l}\text { Cetylpyridinium bromide } \\
\text { modified Montmorillonite }\end{array}$ & $\begin{array}{l}\text { Dosage: } 50 \mathrm{mg} / \mathrm{L} \text {, contact time: } 60 \mathrm{~min} \text {, } \\
25^{\circ} \mathrm{C}, 150 \mathrm{rpm}, \mathrm{pH} 4\end{array}$ & 6.54 & - & [44] \\
\hline $\begin{array}{l}\text { Modified wheat straw } \\
\text { Hydrotalcite }\end{array}$ & $\begin{array}{l}\text { Dosage: } 5-10 \mathrm{mg} / \mathrm{L} \text {; contact time: } 24 \mathrm{~h} \text {, } \\
30{ }^{\circ} \mathrm{C}, 250 \mathrm{rpm}, \mathrm{pH} 6\end{array}$ & - & 17 & [45] \\
\hline $\begin{array}{c}\text { Hydrotalcite } \\
\text { sepiolite-supported nanoscale } \\
\text { zero-valent iron (S-NZVI) }\end{array}$ & $\begin{array}{l}\text { Dosage: } 0.05-3.2 \mathrm{~g} / \mathrm{L} \text { contact time: } \\
11 \mathrm{~min}, 28^{\circ} \mathrm{C}, 200 \mathrm{rpm}, \mathrm{pH} 6\end{array}$ & & 43.86 & [23] \\
\hline $\mathrm{TiO}_{2} @ \mathrm{MIL}-101$ core-shell & Dosage: $150 \mathrm{mg} / \mathrm{L}$ contact time: $4 \mathrm{~h}$ & 19.23 & - & [46] \\
\hline Chitosan/alumina composite & $\begin{array}{l}\text { Dosage: } 10 \mathrm{mg} / \mathrm{L} \text { contact time: } 60 \mathrm{~min} \text {, } \\
303^{\circ} \mathrm{C}, 200 \mathrm{rpm}, \mathrm{pH} 4\end{array}$ & - & 6.127 & {$[47]$} \\
\hline Nano-hydrotalcite $\mathrm{SiO}_{2}$ composite & Dosage: $1 \mathrm{~g} / \mathrm{L}$ contact time: $24 \mathrm{~h}$ & 35 & - & [48] \\
\hline Chitosan/organic rectorite- $\mathrm{Fe}_{3} \mathrm{O}_{4}$ & $\begin{array}{l}\text { Dosage: } 40 \mathrm{mg} / \mathrm{L} \text { contact time: } 80 \mathrm{~min} \text {, } \\
25^{\circ} \mathrm{C}, 200 \mathrm{rpm}, \mathrm{pH} 3\end{array}$ & 5.56 & & [49] \\
\hline
\end{tabular}

\subsection{Adsorption Mechanism}

FT-IR and XPS investigations were used to study the composition of ppy@magnetic chitosan before and after the adsorption of $\mathrm{MO}$ and $\mathrm{Cr}$ (VI) to determine the mechanisms of pollutant removal. FT-IR of ppy@magnetic chitosan nanocomposite before and after adsorption of $\mathrm{MO}$ and $\mathrm{Cr}(\mathrm{VI})$ is shown in Figure 7a. The MO characteristic stretching bands corresponding to $\mathrm{C}-\mathrm{C}, \mathrm{C}-\mathrm{N}, \mathrm{S}=\mathrm{O}$, and $\mathrm{C}-\mathrm{H}$ appear at $1607,1369,1121$, and $826 \mathrm{~cm}^{-1}$ [50] in FT-IR results of ppy@magnetic chitosan adsorbed MO. The slight displacement of bands from their locations was likely observed in FT-IR of ppy@magnetic chitosan adsorbed Cr (VI). In order to approve these results, full range XPS before and after the adsorption of target pollutants was used to identify the adsorbed species over the adsorbent as shown in Figure 7b. The MO and $\mathrm{Cr}(\mathrm{VI})$ characteristic peaks appeared as shown in Figure $7 \mathrm{~b}$, indicating the effective accumulation of $\mathrm{Cr}(\mathrm{VI})$ and $\mathrm{MO}$ over the adsorbent surface through the adsorption process.

Furthermore, the XPS spectrum was used to identify the adsorbed species of chromium ions (Figure 8a). XPS analysis showed two satellite bands of $\mathrm{Cr}$ (VI) and $\mathrm{Cr}$ (III) that appear at 577 and $587 \mathrm{eV}$, respectively. 


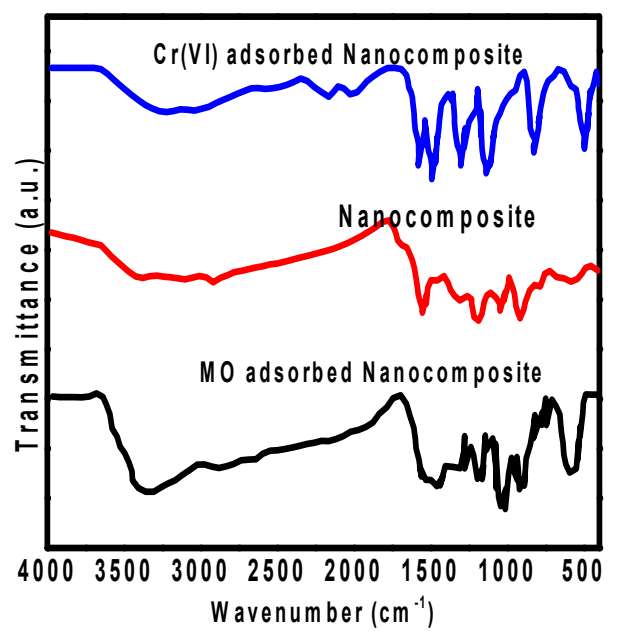

(a)

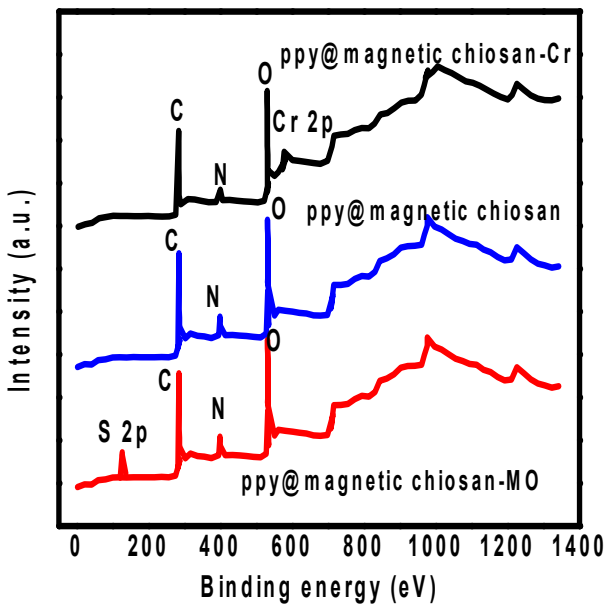

(b)

Figure 7. (a) FT-IR and (b) full range XPS spectrum of ppy@magnetic chitosan before and after Cr (VI) and MO adsorption.

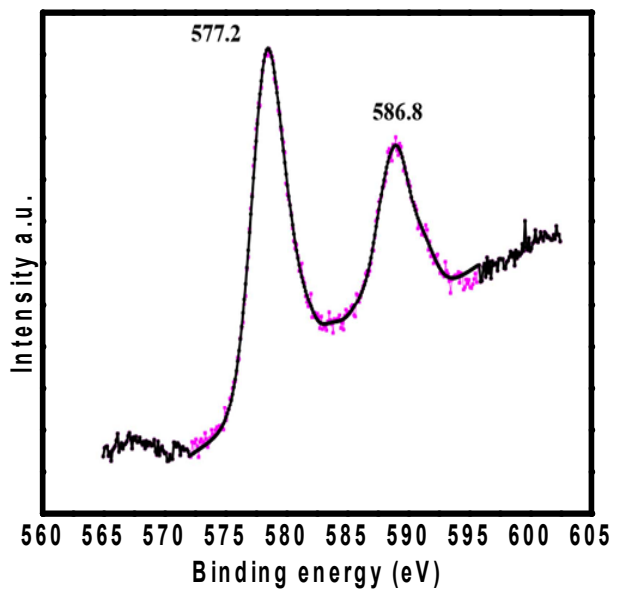

(a)

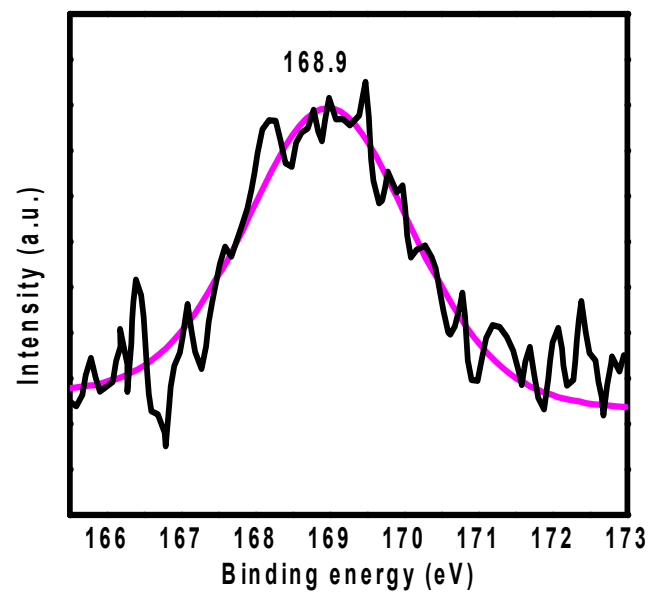

(b)

Figure 8. XPS spectra of ppy@magnetic chitosan after Cr (VI) adsorption (a) and MO adsorption (b).

These results suggested that $\mathrm{Cr}$ (III) ions are present as chromium species over the surface of the adsorbent. Additionally, the existence of satellite bands of both $\mathrm{Cr}(\mathrm{VI})$ and $\mathrm{Cr}$ (III) confirmed the adsorption of Cr (VI) over ppy@magnetic chitosan besides the chemical reduction of $\mathrm{Cr}$ (VI) to $\mathrm{Cr}$ (III) during the adsorption. Subsequently, the chromium removing mechanism can be explained as follows: under acidic conditions, the NH-functional groups were protonated followed by the adsorption of $\mathrm{Cr}(\mathrm{VI})$ species $\left(\mathrm{HCrO}_{4}{ }^{-}\right)$over the adsorbent via bonding with nitrogen species and via electrostatic interactions.

This chemical bonding associated with the oxidation of $-\mathrm{NH}$ - to $=\mathrm{N}$ - was subsequently accompanied by the reduction of hexavalent chromium to $\mathrm{Cr}$ (III). The redox activity of $=\mathrm{N}-/-\mathrm{NH}$ - pairs is responsible for the reduction of $\mathrm{Cr}$ (VI) in addition to their minor oxidation potential compared to the $\mathrm{Cr}$ (III)/ $\mathrm{Cr}$ (VI) redox pair. In addition, few $\mathrm{Cr}$ (III) species may be dissolved in water, and others could be removed via complexation with ppy@magnetic chitosan nitrogen functional groups. On the other hand, the XPS spectrum of ppy@magnetic chitosan after the adsorption of MO showed a satellite peak at $169 \mathrm{eV}$, which indicated the adsorption of MO over the binding sites of the nanocomposite. In general, the redox activity of ppy@magnetic chitosan, besides the existence of different functional groups over its surface, gave the adsorbent amazing in situ chemical reduction properties 
and adsorption toward $\mathrm{Cr}(\mathrm{VI})$ and $\mathrm{MO}$ removal from aqueous solution. Consequently, this innovative adsorbent could be used for water detoxification from pollutants.

\section{Conclusions}

In this study, a novel ppy@magnetic chitosan nanocomposite was synthesized. This novel adsorbent contained magnetic $\mathrm{Fe}_{3} \mathrm{O}_{4}$ nanoparticles and several $\mathrm{N}$-containing functional groups giving it an effective application for water detoxification from both $\mathrm{MO}$ and $\mathrm{Cr}$ (VI). This nanocomposite was successfully characterized using different techniques including SEM, TEM, TGA XRD, and FT-IR. The effect of different factors on the adsorption of $\mathrm{MO}$ and $\mathrm{Cr}(\mathrm{VI})$ over the synthesized nanocomposite was studied, including contact time, $\mathrm{pH}$, and co-existed ions. The study of the contact time effect indicated that the adsorption system was chemically rate-controlled. The $\mathrm{pH}$ effect study revealed that $\mathrm{MO}$ and $\mathrm{Cr}$ (VI) adsorption over the studied adsorbent was $\mathrm{pH}$ dependent and more suitable for an acidic environment at $\mathrm{pH}$ between 2 and 4.5. The study of the co-existing ions effect revealed that the most affected co-ion on adsorption efficiency was sulfate, while bicarbonate had the lowest effect. The adsorption isotherm suggested monolayer adsorption of $\mathrm{MO}$ and $\mathrm{Cr}(\mathrm{VI})$ over a polymeric-inorganic nanocomposite due to its good fit with the Langmuir isotherm. $\mathrm{MO}$ and $\mathrm{Cr}(\mathrm{VI})$ maximal removal efficiencies over this magnetic polymer nanocomposite reached 95 and $105 \mathrm{mg} / \mathrm{g}$, respectively. The reusability study using $0.1 \mathrm{M} \mathrm{NaOH}$ as eluent also indicated an excellent reusability of the nanocomposite up to 5 successive cycles with a slight reduction in the removal efficiency toward $\mathrm{MO}$ and $\mathrm{Cr}(\mathrm{VI})$, which was attributed to the loss of functional group activity. FT-IR and XPS studies approved the successful adsorption of both $\mathrm{MO}$ and $\mathrm{Cr}(\mathrm{VI})$ over the adsorbent surface in addition to the reduction of $\mathrm{Cr}$ (VI) to Cr (III). Finally, we can conclude that ppy@magnetic chitosan nanocomposite is a promising adsorbent for removing $\mathrm{MO}$ and $\mathrm{Cr}(\mathrm{VI})$ from water.

Author Contributions: Conceptualization A.A., N.S.A., K.M.K., F.M.A., M.A.T., and F.B.R.; methodology A.A., N.S.A., K.M.K., F.M.A., M.A.T. and F.B.R.; formal analysis; data curation A.A., N.S.A., K.M.K., F.M.A., M.A.T., and F.B.R.; Writing—original draft preparation, A.A., N.S.A., K.M.K., F.M.A., and M.A.T.; writing-review and editing, A.A., N.S.A., K.M.K., F.M.A., M.A.T., and F.B.R.; visualization; F.B.R. All authors have read and agreed to the published version of the manuscript.

Funding: This research was funded by Deanship of Scientific Research at King Khalid University.

Institutional Review Board Statement: Not applicable.

Informed Consent Statement: Not applicable.

Data Availability Statement: Data sharing is not applicable.

Acknowledgments: The authors extend their appreciation to the Deanship of Scientific Research at King Khalid University for funding this work through research groups program under grant number R.G.P.2/157/42. Also, this research was funded by the Deanship of Scientific Research at Princess Nourah bint Abdulrahman University through the Fast-track Research Funding Program.

Conflicts of Interest: The authors declare no conflict of interest.

\section{References}

1. Tahoon, M.A.; Siddeeg, S.M.; Salem Alsaiari, N.; Mnif, W.; Ben Rebah, F. Effective heavy metals removal from water using nanomaterials: A review. Processes 2020, 8, 645. [CrossRef]

2. Siddeeg, S.M.; Tahoon, M.A.; Ben Rebah, F. Agro-industrial waste materials and wastewater as growth media for microbial bioflocculants production: A review. Mater. Res. Express 2019, 7, 012001. [CrossRef]

3. Siddeeg, S.M.; Tahoon, M.A.; Alsaiari, N.S.; Shabbir, M.; Ben Rebah, F. Application of Functionalized Nanomaterials as Effective Adsorbents for the Removal of Heavy Metals from Wastewater: A Review. Curr. Anal. Chem. 2021, 17, 4-22. [CrossRef]

4. Li, K.; Miwornunyuie, N.; Chen, L.; Jingyu, H.; Amaniampong, P.S.; Ato Koomson, D.; Ewusi-Mensah, D.; Xue, W.; Li, G.; Lu, H. Sustainable Application of ZIF-8 for Heavy-Metal Removal in Aqueous Solutions. Sustainability 2021, 13, 984. [CrossRef]

5. Mohd Makhtar, N.S.; Idris, J.; Musa, M.; Andou, Y.; Ku Hamid, K.H.; Puasa, S.W. Plant-Based Tacca leontopetaloides Biopolymer Flocculant (TBPF) Produced High Removal of Heavy Metal Ions at Low Dosage. Processes 2021, 9, 37. [CrossRef]

6. Khalil, U.; Shakoor, M.B.; Ali, S.; Ahmad, S.R.; Rizwan, M.; Alsahli, A.A.; Alyemeni, M.N. Selective Removal of Hexavalent Chromium from Wastewater by Rice Husk: Kinetic, Isotherm and Spectroscopic Investigation. Water 2021, 13, 263. [CrossRef] 
7. Campisi, S.; Evangelisti, C.; Postole, G.; Gervasini, A. Combination of interfacial reduction of hexavalent chromium and trivalent chromium immobilization on tin-functionalized hydroxyapatite materials. Appl. Surf. Sci. 2021, 539, 148227. [CrossRef]

8. Athira, T.; Roshith, M.; Babu, T.S.; Kumar, D.V.R. Fibrous red phosphorus as a non-metallic photocatalyst for the effective reduction of $\mathrm{Cr}(\mathrm{VI})$ under direct sunlight. Mater. Lett. 2021, 283, 128750. [CrossRef]

9. WHO. Guidelines for Drinking Water Quality, 4th ed.; WHO: Geneva, Switzerland, 2011.

10. Mystrioti, C.; Koursari, S.; Xenidis, A.; Papassiopi, N. Hexavalent Chromium Reduction by Gallic Acid. Chemosphere 2021, 273, 129737. [CrossRef] [PubMed]

11. Ihlenburg, R.B.; Lehnen, A.-C.; Koetz, J.; Taubert, A. Sulfobetaine Cryogels for Preferential Adsorption of Methyl Orange from Mixed Dye Solutions. Polymers 2021, 13, 208. [CrossRef]

12. Li, Y.; Deng, M.; Wang, X.; Wang, Y.; Li, J.; Xia, S.; Zhao, J. In-situ remediation of oxytetracycline and Cr (VI) co-contaminated soil and groundwater by using blast furnace slag-supported nanosized Fe0/FeSx. Chem. Eng. J. 2021, 412, 128706. [CrossRef]

13. Stern, C.M.; Jegede, T.O.; Hulse, V.A.; Elgrishi, N. Electrochemical reduction of $\mathrm{Cr}$ (VI) in water: Lessons learned from fundamental studies and applications. Chem. Soc. Rev. 2021, 50, 1642-1667. [CrossRef] [PubMed]

14. Sabri, M.A.; Sara, Z.; Al-Sayah, M.H.; Ibrahim, T.H.; Khamis, M.I.; El-Kadri, O.M. Simultaneous Adsorption and Reduction of $\mathrm{Cr}$ (VI) to $\mathrm{Cr}$ (III) in Aqueous Solution Using Nitrogen-Rich Aminal Linked Porous Organic Polymers. Sustainability 2021, 13, 923. [CrossRef]

15. Gallo-Cordova, A.; Lemus, J.; Palomares, F.J.; Morales, M.; Mazarío, E. Superparamagnetic nanosorbent for water purification: Assessment of the adsorptive removal of lead and methyl orange from aqueous solutions. Sci. Total Environ. 2020, 711, 134644. [CrossRef] [PubMed]

16. Niazi, L.; Lashanizadegan, A.; Sharififard, H. Chestnut oak shells activated carbon: Preparation, characterization and application for $\mathrm{Cr}$ (VI) removal from dilute aqueous solutions. J. Clean. Prod. 2018, 185, 554-561. [CrossRef]

17. Liu, J.; Zhou, Q.; Chen, J.; Zhang, L.; Chang, N. Phosphate adsorption on hydroxyl-iron-lanthanum doped activated carbon fiber. Chem. Eng. J. 2013, 215, 859-867. [CrossRef]

18. Kumar, N.; Reddy, L.; Parashar, V.; Ngila, J.C. Controlled synthesis of microsheets of ZnAl layered double hydroxides hexagonal nanoplates for efficient removal of Cr (VI) ions and anionic dye from water. J. Environ. Chem. Eng. 2017, 5, 1718-1731. [CrossRef]

19. Karthikeyan, P.; Banu, H.A.T.; Meenakshi, S. Removal of phosphate and nitrate ions from aqueous solution using La3+ incorporated chitosan biopolymeric matrix membrane. Int. J. Biol. Macromol. 2019, 124, 492-504. [CrossRef]

20. Anbinder, P.S.; Macchi, C.; Amalvy, J.; Somoza, A. A study of the structural changes in a chitosan matrix produced by the adsorption of copper and chromium ions. Carbohydr. Polym. 2019, 222, 114987. [CrossRef]

21. Kaur, M.; Kaur, N.; Jeet, K.; Kaur, P. $\mathrm{MgFe}_{2} \mathrm{O}_{4}$ nanoparticles loaded on activated charcoal for effective removal of Cr (VI)-A novel approach. Ceram. Int. 2015, 41, 13739-13750. [CrossRef]

22. Yang, Y.; Yang, J.; Du, Y.; Li, C.; Wei, K.; Lu, J.; Chen, W.; Yang, L. Preparation and Characterization of Cationic Water-Soluble Pillar [5] arene-Modified Zeolite for Adsorption of Methyl Orange. ACS Omega 2019, 4, 17741-17751. [CrossRef]

23. Fu, R.; Yang, Y.; Xu, Z.; Zhang, X.; Guo, X.; Bi, D. The removal of chromium (VI) and lead (II) from groundwater using sepiolite-supported nanoscale zero-valent iron (S-NZVI). Chemosphere 2015, 138, 726-734. [CrossRef]

24. Chen, P.; Xie, F.; Tang, F.; McNally, T. Influence of plasticiser type and nanoclay on the properties of chitosan-based materials. Eur. Polym. J. 2021, 144, 110225. [CrossRef]

25. Fan, S.; Liu, Z.; Wu, Y.; Zhang, Y.; Hu, H.; Huang, Z.; Qin, Y.; Liang, J. 3D porous tubular network-structured chitosan-based beads with multifunctional groups: Highly efficient and selective removal of $\mathrm{Cu}^{2+}$. Int. J. Biol. Macromol. 2021, 171, 17-27. [CrossRef] [PubMed]

26. Saravanan, A.; Kumar, P.S.; Govarthanan, M.; George, C.S.; Vaishnavi, S.; Moulishwaran, B.; Kumar, S.P.; Jeevanantham, S.; Yaashikaa, P. Adsorption characteristics of magnetic nanoparticles coated mixed fungal biomass for toxic Cr (VI) ions in aquatic environment. Chemosphere 2021, 267, 129226. [CrossRef] [PubMed]

27. Zeng, H.; Zhai, L.; Zhang, J.; Li, D. As (V) adsorption by a novel core-shell magnetic nanoparticles prepared with Iron-containing water treatment residuals. Sci. Total Environ. 2021, 753, 142002. [CrossRef]

28. Qiu, X.; Wang, S.; Miao, S.; Suo, H.; Xu, H.; Hu, Y. Co-immobilization of laccase and ABTS onto amino-functionalized ionic liquid-modified magnetic chitosan nanoparticles for pollutants removal. J. Hazard. Mater. 2021, 401, 123353. [CrossRef]

29. Ren, Y.; Abbood, H.A.; He, F.; Peng, H.; Huang, K. Magnetic EDTA-modified chitosan $/ \mathrm{SiO}_{2} / \mathrm{Fe}_{3} \mathrm{O}_{4}$ adsorbent: Preparation, characterization, and application in heavy metal adsorption. Chem. Eng. J. 2013, 226, 300-311. [CrossRef]

30. Wang, J.; Pan, K.; He, Q.; Cao, B. Polyacrylonitrile/polypyrrole core/shell nanofiber mat for the removal of hexavalent chromium from aqueous solution. J. Hazard. Mater. 2013, 244, 121-129. [CrossRef]

31. Siddeeg, S.M.; Tahoon, M.A.; Mnif, W.; Ben Rebah, F. Iron oxide/chitosan magnetic nanocomposite immobilized manganese peroxidase for decolorization of textile wastewater. Processes 2020, 8, 5. [CrossRef]

32. Yuvaraj, H.; Woo, M.H.; Park, E.J.; Jeong, Y.T.; Lim, K.T. Polypyrrole $/ \gamma-\mathrm{Fe}_{2} \mathrm{O}_{3}$ magnetic nanocomposites synthesized in supercritical fluid. Eur. Polym. J. 2008, 44, 637-644. [CrossRef]

33. Govindan, S.; Nivethaa, E.; Saravanan, R.; Narayanan, V.; Stephen, A. Synthesis and characterization of chitosan-silver nanocomposite. Appl. Nanosci. 2012, 2, 299-303. [CrossRef]

34. M Siddeeg, S.; A Tahoon, M.; Ben Rebah, F. Simultaneous Removal of Calconcarboxylic Acid, $\mathrm{NH}_{4}{ }^{+}$and $\mathrm{PO}_{4}{ }^{3-}$ from Pharmaceutical Effluent Using Iron Oxide-Biochar Nanocomposite Loaded with Pseudomonas putida. Processes 2019, 7, 800. [CrossRef] 
35. Siddeeg, S.M.; Amari, A.; Tahoon, M.A.; Alsaiari, N.S.; Ben Rebah, F. Removal of meloxicam, piroxicam and Cd+ 2 by $\mathrm{Fe}_{3} \mathrm{O}_{4} / \mathrm{SiO}_{2} /$ glycidyl methacrylate-S-SH nanocomposite loaded with laccase. Alex. Eng. J. 2020, 59, 905-914. [CrossRef]

36. Bhaumik, M.; Maity, A.; Srinivasu, V.; Onyango, M.S. Enhanced removal of Cr (VI) from aqueous solution using polypyrrole $/ \mathrm{Fe}_{3} \mathrm{O}_{4}$ magnetic nanocomposite. J. Hazard. Mater. 2011, 190, 381-390. [CrossRef]

37. Robati, D.; Mirza, B.; Rajabi, M.; Moradi, O.; Tyagi, I.; Agarwal, S.; Gupta, V. Removal of hazardous dyes-BR 12 and methyl orange using graphene oxide as an adsorbent from aqueous phase. Chem. Eng. J. 2016, 284, 687-697. [CrossRef]

38. Li, K.; Li, P.; Cai, J.; Xiao, S.; Yang, H.; Li, A. Efficient adsorption of both methyl orange and chromium from their aqueous mixtures using a quaternary ammonium salt modified chitosan magnetic composite adsorbent. Chemosphere 2016, 154, 310-318. [CrossRef] [PubMed]

39. Chen, S.; Huang, Y.; Han, X.; Wu, Z.; Lai, C.; Wang, J.; Deng, Q.; Zeng, Z.; Deng, S. Simultaneous and efficient removal of Cr (VI) and methyl orange on LDHs decorated porous carbons. Chem. Eng. J. 2018, 352, 306-315. [CrossRef]

40. Karthikeyan, P.; Elanchezhiyan, S.S.; Preethi, J.; Meenakshi, S.; Park, C.M. Mechanistic performance of polyaniline-substituted hexagonal boron nitride composite as a highly efficient adsorbent for the removal of phosphate, nitrate, and hexavalent chromium ions from an aqueous environment. Appl. Surf. Sci. 2020, 511, 145543. [CrossRef]

41. Han, Y.; Cao, X.; Ouyang, X.; Sohi, S.P.; Chen, J. Adsorption kinetics of magnetic biochar derived from peanut hull on removal of $\mathrm{Cr}(\mathrm{VI})$ from aqueous solution: Effects of production conditions and particle size. Chemosphere 2016, 145, 336-341. [CrossRef]

42. Zhao, P.; Zhang, R.; Wang, J. Adsorption of methyl orange from aqueous solution using chitosan/diatomite composite. Water Sci. Technol. 2017, 75, 1633-1642. [CrossRef]

43. Annadurai, G.; Juang, R.-S.; Lee, D.-J. Use of cellulose-based wastes for adsorption of dyes from aqueous solutions. J. Hazard. Mater. 2002, 92, 263-274. [CrossRef]

44. Hu, B.; Luo, H. Adsorption of hexavalent chromium onto montmorillonite modified with hydroxyaluminum and cetyltrimethylammonium bromide. Appl. Surf. Sci. 2010, 257, 769-775. [CrossRef]

45. Lazaridis, N.; Pandi, T.; Matis, K. Chromium (VI) removal from aqueous solutions by Mg-Al-CO $\mathrm{C}_{3}$ hydrotalcite: Sorptiondesorption kinetic and equilibrium studies. Ind. Eng. Chem. Res. 2004, 43, 2209-2215. [CrossRef]

46. Chang, N.; Zhang, H.; Shi, M.-S.; Li, J.; Shao, W.; Wang, H.-T. Metal-organic framework templated synthesis of TiO $2 @ \mathrm{MIL}-101$ core-shell architectures for high-efficiency adsorption and photocatalysis. Mater. Lett. 2017, 200, 55-58. [CrossRef]

47. Gandhi, M.R.; Meenakshi, S. Preparation and characterization of La (III) encapsulated silica gel/chitosan composite and its metal uptake studies. J. Hazard. Mater. 2012, 203, 29-37. [CrossRef] [PubMed]

48. Pérez, E.; Ayele, L.; Getachew, G.; Fetter, G.; Bosch, P.; Mayoral, A.; Díaz, I. Removal of chromium (VI) using nanohydrotalcite/SiO2 composite. J. Environ. Chem. Eng. 2015, 3, 1555-1561. [CrossRef]

49. Zeng, L.; Xie, M.; Zhang, Q.; Kang, Y.; Guo, X.; Xiao, H.; Peng, Y.; Luo, J. Chitosan/organic rectorite composite for the magnetic uptake of methylene blue and methyl orange. Carbohydr. Polym. 2015, 123, 89-98. [CrossRef]

50. Deng, L.; Shi, Z.; Peng, X.; Zhou, S. Magnetic calcinated cobalt ferrite/magnesium aluminum hydrotalcite composite for enhanced adsorption of methyl orange. J. Alloys Compd. 2016, 688, 101-112. [CrossRef] 